\title{
Childhood Multisystem Inflammatory Syndrome: An Emerging Disease with Prominent Cardiovascular Involvement-A Scoping Review
}

\author{
Amit Malviya $^{1}$ (D) Animesh Mishra ${ }^{1}$
}

Accepted: 16 November 2020 / Published online: 7 January 2021

(C) Springer Nature Switzerland AG 2021

\begin{abstract}
Multisystem inflammatory syndrome in children (MIS-C) or paediatric inflammatory multisystem syndrome temporally associated with SARS-CoV-2 (PIMS-TS) is an emerging disease in children affected with severe acute respiratory syndrome coronavirus-2 (SARS-CoV-2) infection and thought to be an immune-mediated post-infectious complication of SARS-CoV-2. The disease presentation is similar to Kawasaki disease but has certain distinguishing features. The exact pathogenesis is still not clear but an aberrant immune response, antibody-mediated vascular damage and virus-mediated abnormal type I and III interferon-gamma response are thought to be responsible. Most children who are previously healthy present after $2-4$ weeks of SARS-CoV-2 infections with febrile illness of short duration with prominent gastrointestinal, cardiac and hematologic manifestations, progressing to vasoplegic shock, requiring vasopressor therapy. Cardiovascular involvement is prominently marked by acute myocardial injury/myocarditis and the development of coronary artery aneurysms. Laboratory markers of inflammation are elevated uniformly. Most children require intensive care, and few need invasive ventilation. The treatment mainly consists of anti-inflammatory and immunomodulatory therapy like intravenous immunoglobulins and steroids. The overall prognosis is good and reported mortality rates are $0-4 \%$.
\end{abstract}

Keywords Multisystem inflammation $\cdot$ Paediatric $\cdot$ Covid-19 $\cdot$ Cardiovascular $\cdot$ Coronary aneurysm

\section{List of Abbreviations}

ACE 2 Angiotensin-converting enzyme 2

BNP B-type natriuretic peptide

This article is part of the Topical Collection on Covid-19

\section{What is known}

- Multisystem inflammatory syndrome in children (MIS-C) is thought to

be an immune-mediated post-infectious complication of SARS-CoV -2.

- The disease presentation is similar to Kawasaki disease but has certain distinguishing features.

\section{What is new?}

- An aberrant immune response, antibody-mediated vascular damage and virus-mediated abnormal type I and III interferon-gamma response are thought to be responsible.

- Unlike KD ,MIS-C is reported to be affecting children predominantly older than 5 years, more frequent cardiovascular involvement, and if proven, SARS-CoV-2 will be the first known virus to cause coronary aneurysms directly.

Amit Malviya

dramit_malviya@rediffmail.com

Animesh Mishra

animesh.shillong@gmail.com
CDC

Covid-19

CRP Centers for Disease Control and Prevention Coronavirus disease 2019

C-reactive protein 


\begin{tabular}{|c|c|}
\hline ESR & Erythrocyte sedimentation rate \\
\hline IL-6 & Interleukin 6 \\
\hline KD & Kawasaki disease \\
\hline LDH & Lactic acid dehydrogenase \\
\hline MIS-C & $\begin{array}{l}\text { Multisystem inflammatory } \\
\text { syndrome in children }\end{array}$ \\
\hline NT-Pro-BNP & $\begin{array}{l}\text { N-terminal pro-hormone B-type } \\
\text { natriuretic peptide }\end{array}$ \\
\hline PIMS-TS & $\begin{array}{l}\text { Paediatric inflammatory multisystem } \\
\text { syndrome temporally associated } \\
\text { with SARS-CoV-2 }\end{array}$ \\
\hline RT-PCR & $\begin{array}{l}\text { Reverse transcriptase-polymerase } \\
\text { chain reaction }\end{array}$ \\
\hline SARS-CoV-2 & $\begin{array}{l}\text { Severe acute respiratory } \\
\text { syndrome coronavirus- } 2\end{array}$ \\
\hline
\end{tabular}

\section{Introduction}

The ongoing pandemic of severe acute respiratory syndrome coronavirus-2 (SARS-CoV-2)-related coronavirus disease 2019 (Covid-19) is evolving at a rapid pace, and reports of newer manifestations of the disease are being reported worldwide. Children and adolescents affected by Covid-19 appear to have milder symptoms in the majority, less frequent severe disease and fewer hospitalizations as compared with adults [1-3] except for the infants and children with underlying comorbidities including congenital heart disease, who are at highest risk of complications of Covid-19 [4-6]. Recently several reports have described previously asymptomatic children affected with SARS-CoV-2 infection manifesting as a systemic hyperinflammatory status with multiorgan involvement (sometimes features reminiscent of Kawasaki disease) and prominent cardiogenic shock with myocardial dysfunction often requiring intensive care support. In Europe, it was termed as paediatric inflammatory multisystem syndrome temporally associated with SARS-CoV-2 or PIMS-TS. The condition has now rapidly evolved into a clinically wellrecognized syndrome distinct from Kawasaki disease and is also termed as multisystem inflammatory syndrome in children (MIS-C) by the Centers for Disease Control and Prevention (CDC), USA [7-19]. Until now children were thought to have been largely spared from severe Covid-19 disease, but the emergence of this serious condition has implications on balance of healthcare resources and counselling of parents. The notable absence of severe pulmonary, renal and coagulation system involvement with prominent cardiac involvement is some of the differentiating features from severe Covid-19 in the adult population. MIS-C is being associated with the development of coronary aneurysm in affected children, and if it is proven then SARS-Cov- 2 will be the first virus to be proven to do so.

\section{Case Definition}

The Centers for Disease Control and Prevention (CDC), USA, provided a case definition [20] for MIS-C on May 14, 2020. "An individual aged $<21$ years presenting with fever, laboratory evidence of inflammation, and evidence of clinically severe illness requiring hospitalization, with multisystem $(>2)$ organ involvement (cardiac, renal, respiratory, hematologic, gastrointestinal, dermatologic or neurological); AND no alternative plausible diagnoses; AND positive for current or recent SARS-CoV-2 infection by Reverse Transcriptase -Polymerase Chain Reaction (RTPCR), serology, or antigen test; or Covid-19 exposure within the 4 weeks before the onset of symptoms. Fever $>38.0^{\circ} \mathrm{C}$ for $\geq 24$ hours, or report of subjective fever lasting $\geq 24$ hours. Including, but not limited to, one or more of the following: an elevated Creactive protein (CRP), erythrocyte sedimentation rate (ESR), fibrinogen, procalcitonin, d-dimer, ferritin, lactic acid dehydrogenase (LDH), or interleukin 6 (IL-6), elevated neutrophils, reduced lymphocytes and low albumin Some individuals may fulfil full or partial criteria for Kawasaki disease but should be reported if they meet the case definition for MIS-C. Consider MIS-C in any pediatric death with evidence of SARS-CoV-2 infection."

While the WHO case definition [14] is concurrent with CDC case definition, the case definition provided by the Royal College of Paediatrics and Child Health [13] differs from the CDC case definition as it does not require SARSCoV-2 PCR testing to be positive as an essential criterion. Furthermore, the CDC definition requires evidence of SARS-CoV-2 infection or exposure, which may not be always possible as many infected children may be asymptomatic initially and might not be tested; also the antibody testing is not so routinely available in many countries. It must be kept in mind that above case definitions are meant to be sensitive and in clinical practice, another diagnosis (discussed below in differential diagnosis section) should be conclusively ruled out before labelling the case as MIS-C.

\section{Epidemiology}

The actual incidence of MIS-C is currently not known because most children with acute Covid-19 have mild symptoms or may have asymptomatic SARS-CoV-2 infection and MIS-C may follow either Covid-19 or asymptomatic infection. Furthermore, children are tested less frequently than adults [2]. However, some recent surveillance studies $[18,19]$ have indicated that it is not a common complication of Covid-19. The initial cluster of children suffering from hyperimmune response to SARS-CoV-2 infection was reported from London [7] and subsequently from various countries like the USA, Canada and other parts of the European Union [9, 13, 14, 20, 21]. 
The median age of affected children varies from 8 to 10 years (range 1-17 years) in various reported studies with slight male predilection, and proportionally more black and Hispanic children are affected. Out of all the reported cases, almost three fourths of the children were previously healthy although some studies have reported more prevalence of obesity, overweight and asthma in their observational cohorts. This pattern is in stark contrast with acute Covid-19 illness in children where infants and children with underlying medical conditions are prone to severe disease [4]. There is a definite lag period observed between the peaks of infection in community and peak of admissions for MIS-C cases [10, 18-20, 22]. The time from onset of symptoms of Covid-19 to hospitalization for MIS-C varies widely among studies, but it ranges from 6 to 51 days $[18,19]$. Majority of the children exhibit evidence of SARS-CoV-2 infection, and the most common pattern is positivity with serological tests for antibody detection with negative reverse transcriptasepolymerase chain reaction (RT-PCR) for viral detection (Table 1) [10-12, 18, 19, 22, 23].

\section{Clinical Manifestations}

MIS-C is a recently recognized disease with a wide spectrum of manifestations. Initially, the most severe forms were reported, but now it is becoming increasingly clear that disease severity varies from milder forms to very severe illness manifesting with shock and multiorgan failure. Review of available cases and data suggests that the syndrome of MIS-C may follow one of the following three common patterns: firstly, a persistent febrile illness with elevated biomarkers for inflammation but no major organ dysfunction; secondly, acute myocarditis like presentation with shock and myocardial dysfunction and consequent renal or respiratory failure; and thirdly, very similar to Kawasaki disease with coronary aneurysms and some of which progress to shock requiring vasopressors. The second and third patterns are most commonly reported. However, the manifestations are overlapping, and the patterns of presentations are mutually not exclusive.

MIS-C occurs 2 to 4 weeks after infection with SARS-CoV-2 infection. Majority of the children present with persistent fever of more than 4 days duration with gastrointestinal symptoms like abdominal pain, vomiting and diarrhoea. Other common manifestations include cutaneous rashes, conjunctivitis and mucus membrane involvement in more than half of children. Neurocognitive symptoms, respiratory symptoms and features of congestive heart failure are present in variable frequencies at presentation. Pulmonary involvement at presentation (e.g. cough) is not a common presentation, and usually respiratory symptoms are mild at presentation [10-19, 23]. This pattern is in contrast to the pattern of respiratory involvement in children admitted to hospital with acute Covid illness and having prominent respiratory illness [1-3].

In the course of illness majority of these children, go on to develop vasodilatory/distributive shock which is often not responsive to fluid resuscitation requiring vasopressors and in minority extracorporeal membrane oxygenation support. Around $20 \%$ of the patients go on to develop a severe critical illness requiring mechanical ventilation support. The reported incidence of complications are as follows: shock (50-80\%), myocardial dysfunction (51-100\%), acute kidney injury (22$70 \%)$, acute hepatic failure $(20-30 \%)$ and acute respiratory failure (mostly secondary to cardiogenic causes) requiring invasive/non-invasive ventilation (40-50\%) [15-19, 23].

In one of the largest reported series of MIS-C cases [18], the organ system involvement included the gastrointestinal system in $92 \%$, cardiovascular in $80 \%$, hematologic in $76 \%$, mucocutaneous in $74 \%$ and respiratory in $70 \%$. The median duration of hospitalization was 7 days. Almost $80 \%$ received intensive care and half of them require vasopressor support. Coronary artery aneurysms ( $\mathrm{z}$ scores $\geq 2.5$ ) were documented in onetenth of the patients, and Kawasaki's disease-like features were documented in $40 \%$. The comparative features of all major reported studies are presented in Table 2. Notably, some studies have reported variations in symptoms and organ involvement according to age [19]. Dermatologic manifestations were more common in children less than five years of age, the prevalence of myocarditis was highest in children above 10 years of age. Prevalence of gastrointestinal involvement was high in all age groups across all studies. The acute myocardial injury/myocarditis associated with MIS-C, in contrast to adults with SARS-CoV-2 related myocarditis, is reported to be milder, associated with mild to moderate troponin elevations and rapid restoration of left ventricular function.

\section{Laboratory Parameters}

The most common findings are abnormal blood cell counts (lymphocytopenia, neutrophilia, thrombocytopenia and low red blood cell counts), elevated markers of inflammation 1 (C-reactive protein, erythrocyte sedimentation rate, D-dimer, fibrinogen, ferritin, procalcitonin and interleukin -6), elevated markers of cardiac injury (cardiac troponins, NT-Pro-BNP, BNP), abnormal liver function tests and hypertriglyceridemia (Table 3). The severity of disease correlates well with the elevation in inflammatory biomarkers [12]. During the course of illness, these inflammatory makers tend to normalize over 4-5 days of admission [23]. Imaging studies like X-ray, computerized tomography and ultrasound usually reveal the 


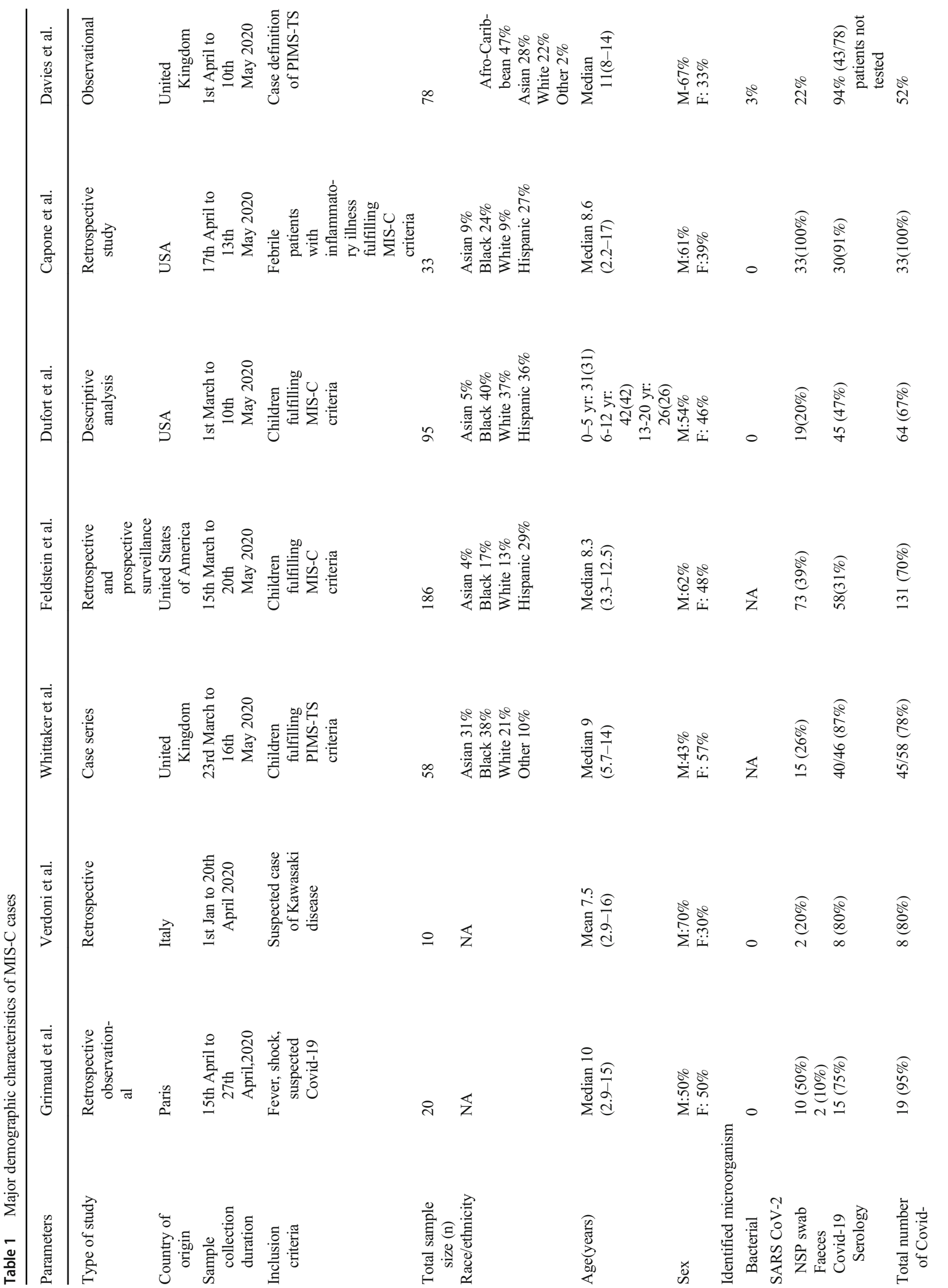




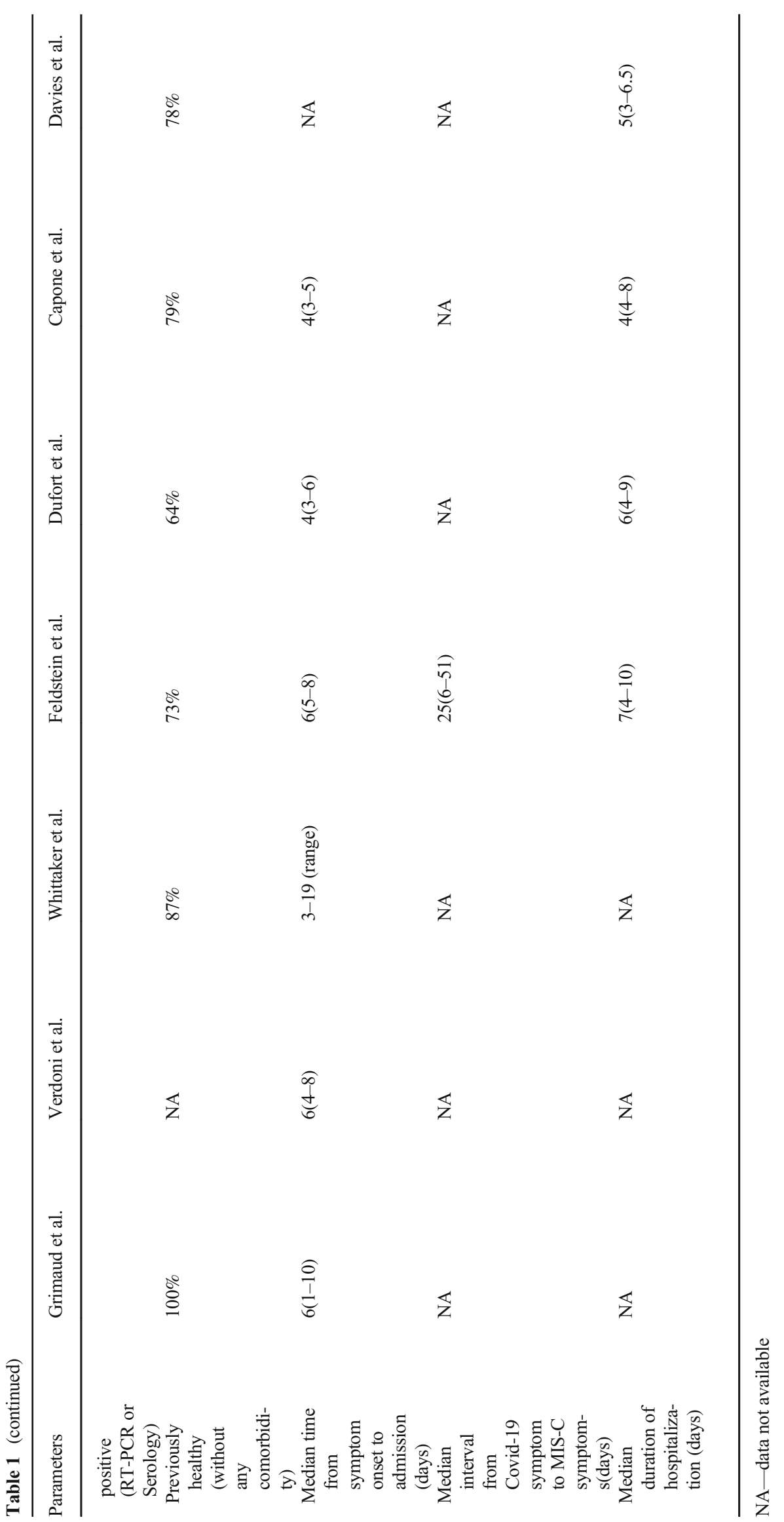


Table 2 Clinical characteristics of MIS-C

\begin{tabular}{|c|c|c|c|c|c|c|c|}
\hline Parameters & Grimaud et al. & $\begin{array}{l}\text { Verdoni } \\
\text { et al. }\end{array}$ & $\begin{array}{l}\text { Whittaker } \\
\text { et al. }\end{array}$ & $\begin{array}{l}\text { Feldstein } \\
\text { et al. }\end{array}$ & $\begin{array}{l}\text { Dufort } \\
\text { et al. }\end{array}$ & $\begin{array}{l}\text { Capone } \\
\text { et al. }\end{array}$ & Davies et al. \\
\hline \multicolumn{8}{|l|}{ Clinical features (\%) } \\
\hline Fever & $100 \%$ & $100 \%$ & $100 \%$ & $100 \%$ & $100 \%$ & $100 \%$ & $100 \%$ \\
\hline \multicolumn{8}{|l|}{ Any Gastrointestinal } \\
\hline Involvement & $100 \%$ & $60 \%$ & $53 \%$ & $92 \%$ & $80 \%$ & $97 \%$ & $90 \%$ \\
\hline Abdominal pain & $100 \%$ & NA & $53 \%$ & NA & $61 \%$ & NA & $62 \%$ \\
\hline Diarrhoea & NA & $60 \%$ & $52 \%$ & NA & $49 \%$ & NA & $64 \%$ \\
\hline Vomiting & $100 \%$ & NA & $45 \%$ & NA & $58 \%$ & NA & $63 \%$ \\
\hline $\begin{array}{l}\text { Any Mucocutaneous } \\
\text { Involvement }\end{array}$ & $50 \%$ & $70 \%$ & $52 \%$ & $74 \%$ & $62 \%$ & $64 \%$ & NA \\
\hline Skin rash & $50 \%$ & $30 \%$ & $52 \%$ & $59 \%$ & $60 \%$ & NA & $45 \%$ \\
\hline Conjunctivitis & $30 \%$ & $30 \%$ & $45 \%$ & $55 \%$ & $56 \%$ & NA & $29 \%$ \\
\hline Chelitis & $25 \%$ & $60 \%$ & $29 \%$ & $74 \%$ & & NA & NA \\
\hline Adenitis $(>1.5 \mathrm{~cm})$ & $10 \%$ & $10 \%$ & $16 \%$ & $18 \%$ & $6 \%$ & NA & NA \\
\hline Any respiratory symptoms & NA & NA & $21 \%$ & $70 \%$ & $67 \%$ & $52 \%$ & NA \\
\hline Any neurologic involvement & NA & $50 \%$ & $26 \%$ & $6 \%$ & $30 \%$ & $58 \%$ & NA \\
\hline Headache & NA & NA & $26 \%$ & NA & $29 \%$ & NA & \\
\hline Meningeal signs & NA & $40 \%$ & NA & $2 \%$ & NA & NA & \\
\hline GCS median (range) & $15(4-15)$ & Nil & NA & NA & NA & NA & \\
\hline Any cardiac involvement & $100 \%$ & $60 \%$ & $50 \%$ & $80 \%$ & $97 \%$ & $58 \%$ & $87 \%$ \\
\hline Myocarditis & $100 \%$ & NA & $50 \%$ & NA & $53 \%$ & $58 \%$ & NA \\
\hline Aneurysm & 0 & $20 \%$ & $14 \%$ & $8 \%$ & $9 \%$ & $15 \%$ & $\begin{array}{c}23 \% \text { (additional } \\
12.8 \% \text { had } \\
\text { unusually } \\
\text { echogenic } \\
\text { coronaries) }\end{array}$ \\
\hline Any renal involvement & $70 \%$ & NA & $22 \%$ & $7.5 \%$ & $10 \%$ & $70 \%$ & \\
\hline AKI & $70 \%$ & NA & $22 \%$ & $5 \%$ & $10 \%$ & $70 \%$ & \\
\hline Any hematologic involvement & $100 \%$ & $100 \%$ & $100 \%$ & $76 \%$ & $66 \%$ & $82 \%$ & $100 \%$ \\
\hline $\begin{array}{l}\text { Any musculoskeletal } \\
\text { involvement }\end{array}$ & NA & NA & NA & $23 \%$ & $20 \%$ & NA & NA \\
\hline $\begin{array}{l}\text { Major systemic } \\
\text { inflammation }\end{array}$ & $100 \%$ & $100 \%$ & $100 \%$ & $100 \%$ & $100 \%$ & $100 \%$ & $100 \%$ \\
\hline Hypotension & $100 \%$ & $50 \%$ & $50 \%$ & $48 \%$ & $32 \%$ & $76 \%$ & $87 \%$ \\
\hline $\begin{array}{l}\text { Fulfilled Kawasaki } \\
\text { diagnostic criteria }\end{array}$ & $\begin{array}{l}0 \text { (at least one } \\
\text { feature of } \mathrm{KD} \\
\text { found in all } \\
\text { children) }\end{array}$ & $70 \%$ & $22 \%$ & $40 \%$ & $36 \%$ & $64 \%$ & \\
\hline
\end{tabular}

$\mathrm{NA}$ - data not available

typical markers polyserositis like pleural effusion, patches in the lung parenchyma, free fluid in the abdomen, bowel inflammation and mesenteric adenopathy. The echocardiography has an important role to play as many patients exhibit depressed left ventricular ejection fraction, coronary artery aneurysm, dilated coronary arteries, abnormally echogenic coronary arteries, pericardial effusion and mitral regurgitation. The frequency of cardiac involvement varies from 30 to $70 \%$ in various studies and in children presenting with shock initially had the highest chances of having cardiovascular involvement [17].

\section{General Prognosis}

At present limited information is there to comment upon the prognosis and markers of prognosis in MIS-C. Almost 1000 cases have been reported cumulatively worldwide till date, and most of the children have recovered with antiinflammatory treatment with very few fatal outcomes. The reported death rates vary from 0 to $4 \%$. However, the major chunk of patients required intensive care, and some of them were managed with invasive management like ventilatory support, extracorporeal membrane oxygenation and dialysis 


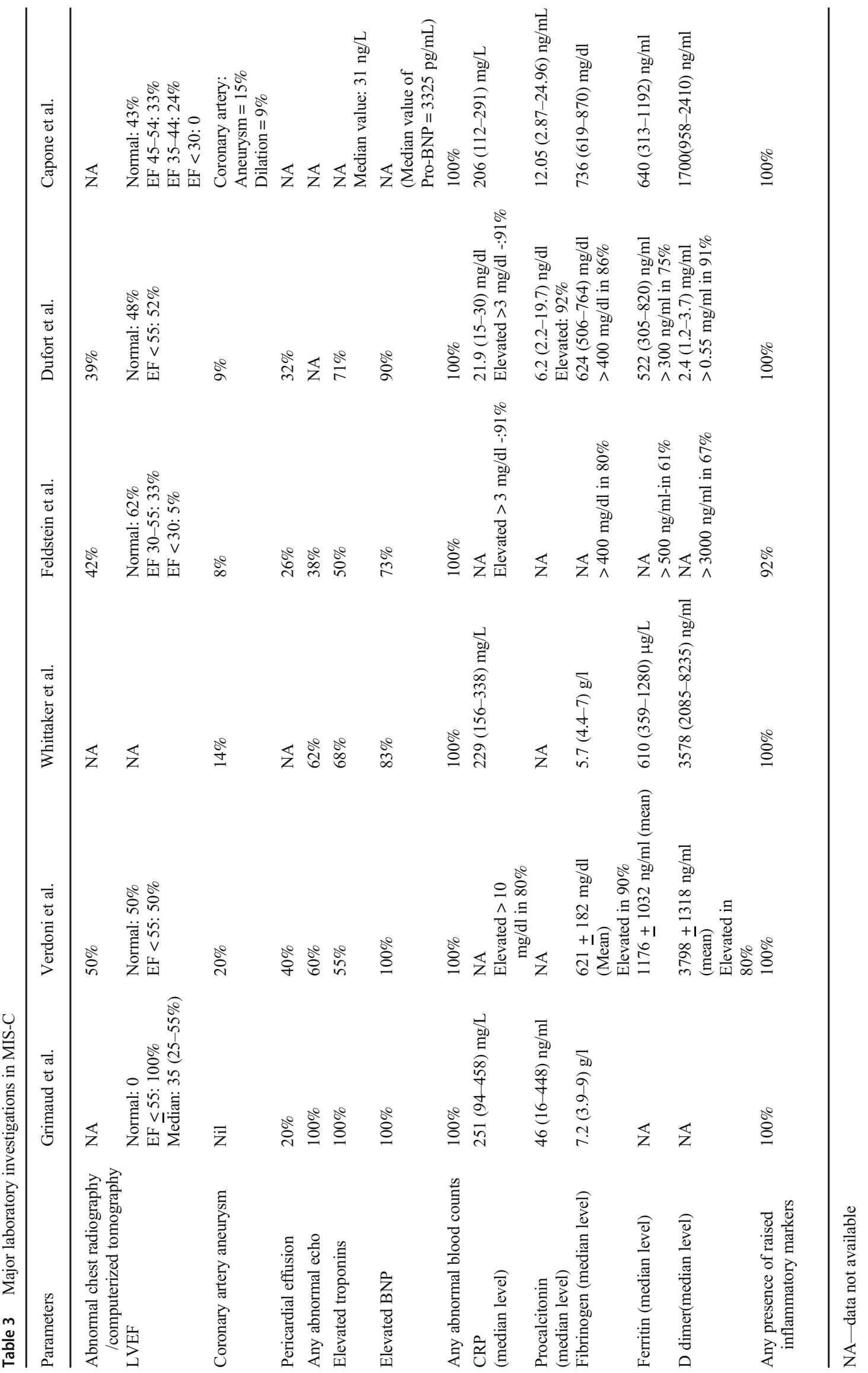


(Table 4). Apart from a few studies which correlate severe disease with inflammatory markers, at present, we do not have enough information on how the disease progress from mild to severe and what are the factors responsible for poor outcomes. None of the available studies has any clear correlations of presenting features, laboratory tests and treatments, with the risk of having coronary artery abnormalities or being invasively ventilated.

\section{Cardiovascular Prognosis}

MIS-C-related myocarditis appears to be less severe as compared with other childhood myocarditis and better response to treatment $[11,21,24]$.

The prognosis and natural history of coronary aneurysm associated with MIS-C are unknown at present. However, a recent study reported that they are largely present at the time of admission, and only a few develop it during the course of hospitalization. Up to onethird of patients may have coronary abnormalities like dilated or abnormally echogenic coronaries, the significance of which is unknown at present, half of such abnormalities disappear before discharge. The biomarkers peak on the second day of admission and show a gradual decline towards normalcy within median 45 days. Importantly this decline precedes the normalization of electrocardiographic changes and recovery of left ventricular function [25]. Thus, the biomarkers may be a useful clinical indicator of recovery. More than half of the children recover their left ventricular ejection fraction before discharge.

\section{Differential Diagnosis}

This rare syndrome shares common features with other paediatric inflammatory conditions including Kawasaki disease, staphylococcal and streptococcal toxic shock syndromes, bacterial sepsis and macrophage activation syndromes which can also present with unusual abdominal symptoms with excessive inflammatory markers.

The disease has a lot of similarity with Kawasaki disease, and in fact, in various studies, 30-70\% of patients had met partial or full criteria, for diagnosing Kawasaki disease. However, there are certain clear differences from Kawasaki disease, like MIS-C is reported to be affecting children predominantly older than 5 years, more frequent cardiovascular involvement and the majority have direct or indirect evidence (suggesting strong temporal relationship) of SARS-CoV-2 infection or exposure. The nature and extent of cardiovascular involvement also differ in both diseases. Firstly, only $5 \%$ of Kawasaki patients require vasopressor support [26], while up to $20-95 \%$ of MIS-C patients require inotropic support in various reports [17-19] [23, 24]. Secondly, the incidence of the coronary aneurysm in Kawasaki disease is more as compared with MIS-C [27]. No data is available about the long-term consequences of this aneurysm of MIS-C as compared with Kawasaki disease, where it is well known to cause myocardial infarction [28]. There are several other clinical and laboratory parameters which can help differentiate Kawasaki disease from MIS-C. The presence of significant abdominal pain, lymphocytopenia, very high NT-Pro-BNP levels (>10,000 pg/ml) and severe myocardial dysfunction favours MIS-C [29, 30].

Table 4 Treatment and outcomes in MIS-C

\begin{tabular}{|c|c|c|c|c|c|c|c|}
\hline Parameters & Grimaud et al. & Verdoni et al. & Whittaker et al. & Feldstein et al. & Dufort et al. & Capone et al & Davies et al. \\
\hline Intensive care & $100 \%$ & NA & $50 \%$ & $80 \%$ & $80 \%$ & $79 \%$ & NA \\
\hline High flow nasal O2 & 5 & NA & NA & $26 \%$ & $16 \%$ & $52 \%$ & $17 \%$ \\
\hline Invasive mechanical ventilation & 40 & NA & $43 \%$ & $20 \%$ & $10 \%$ & $18 \%$ & $46 \%$ \\
\hline Vasopressor support & $95 \%$ & $20 \%$ & $47 \%$ & $48 \%$ & $62 \%$ & $76 \%$ & $83 \%$ \\
\hline ECMO & Nil & NA & $5 \%$ & $4 \%$ & $4 \%$ & NA & $4 \%$ \\
\hline Dialysis & Nil & NA & NA & $3 \%$ & NA & NA & $1 \%$ \\
\hline IVIG & $100 \%$ & $100 \%$ & $71 \%$ & $77 \%$ & $70 \%$ & $100 \%$ & $76 \%$ \\
\hline Any anticoagulation/antiplatelet & NA & $20 \%$ & NA & $47 \%$ & NA & $88 \%$ & $58 \%$ \\
\hline Corticosteroids & $10 \%$ & $80 \%$ & $64 \%$ & $49 \%$ & $64 \%$ & $70 \%$ & $73 \%$ \\
\hline Anti-IL-6 receptor antagonist & $5 \%$ & Nil & NA & $8 \%$ & NA & $9 \%$ & $4 \%$ \\
\hline Anti-IL-1 receptor antagonist & $5 \%$ & Nil & $5 \%$ & $13 \%$ & NA & $12 \%$ & $10 \%$ \\
\hline TNF alpha antagonist & Nil & Nil & $14 \%$ & Nil & NA & $3 \%$ & $9 \%$ \\
\hline Mortality & Nil (all survived) & Nil (all survived) & $2 \%$ & $2 \%$ & $2 \%$ & Nil (all survived) & $3 \%$ \\
\hline
\end{tabular}

NA — data not available 


\section{Pathogenesis of Cardiovascular Involvement}

There is much speculation regarding the relationship of MIS$\mathrm{C}$ to complete or incomplete Kawasaki disease, Kawasaki shock syndrome, bacterial infection related to toxic shock syndrome and macrophage activation syndrome [7, 8, 29, 30]. Combined with the fact that clinical manifestation of MIS-C appears after a lag phase of $2-3$ weeks, the time when viral titres are going down and antibody titres are escalating upwards and most manifestation is related to hyperinflammation similar to the adult population with severe disease $[31,32]$. It is hypothesised that MIS-C is a postinfectious immune-mediated injury consequent to the SARSCoV-2 infection (Fig. 1). Firstly, this hypothesis is supported by the fact that the peak of MIS-C cases occurred after a delay of weeks from community peak $[10,18,19]$ and frequent finding of antibody positivity and negative RT-PCR results $[10,11,18,19,23,30]$ and secondly, the children with MIS-C have a predominantly gastrointestinal presentation of their illness and enterocytes be readily infected by SARSCoV-2 and there is evidence of gastric adenitis in children affected with MIS-C. Similar to the SARS-CoV-1, the IgG antibodies may enhance organ damage and cause a heightened immune response by altering the macrophage activity in acute SARS-CoV-2 infection [33]. Antibodies may accentuate the disease process by facilitating viral entry or replication, the formation of antibody complexes and cellular activation [34]. The pathogenesis of coronary vasculature involvement in MIS-C may also be explained by immune complex-induced vasculitis. Immune complexes evoke inflammatory responses and vascular damage through $\mathrm{Fc}$ gamma receptors or neutrophil activation; similar mechanisms have been shown to operate in closely linked Kawasaki disease [34-37]. However there is a certain limitation to this hypothesis. The antibodies may arise during the second week of infection, and there is a lack of information regarding the specificity of the antibody assays carried out in patients with MIS-C; no control population has been studied to establish an association between SARS-CoV-2, and an MIS-C and finally worsening of illness has not been reported with patients treated with convalescent plasma. Another theory of severe inflammatory response is proposed based on the ability of coronaviruses to block type I and type III interferon responses leading to delayed cytokine storm [38].

Myocardial affection is also a common feature in MIS-C and may be related to high circulating levels of C-reactive protein and Interleukin-6, which is known to be related to myocardial dysfunction in bacterial infections [39]. The disproportionately high elevation of ventricular natriuretic peptides and mild to moderate elevation of troponins have led some investigators to believe that acute heart failure of MIS$\mathrm{C}$ is related more to myocardial oedema and vasoplegia with variable contribution from mild to moderate myocarditis [11, 24]. In this context it is important to note that at present there are no studies available where myocardial biopsy has been done to elucidate the true mechanism of myocardial injury and to rule out active viral replication as the cause of damage to myocytes rather than immune-mediated damage. As for other immune-mediated pathologies in children and closely related Kawasaki disease, various host factors come into play like genetic susceptibility [40]. The hypothesis of genetic susceptibility is supported by the fact that there are no reports of

\section{Initial phase Early infection phase Lag phase Symtomatic phase}
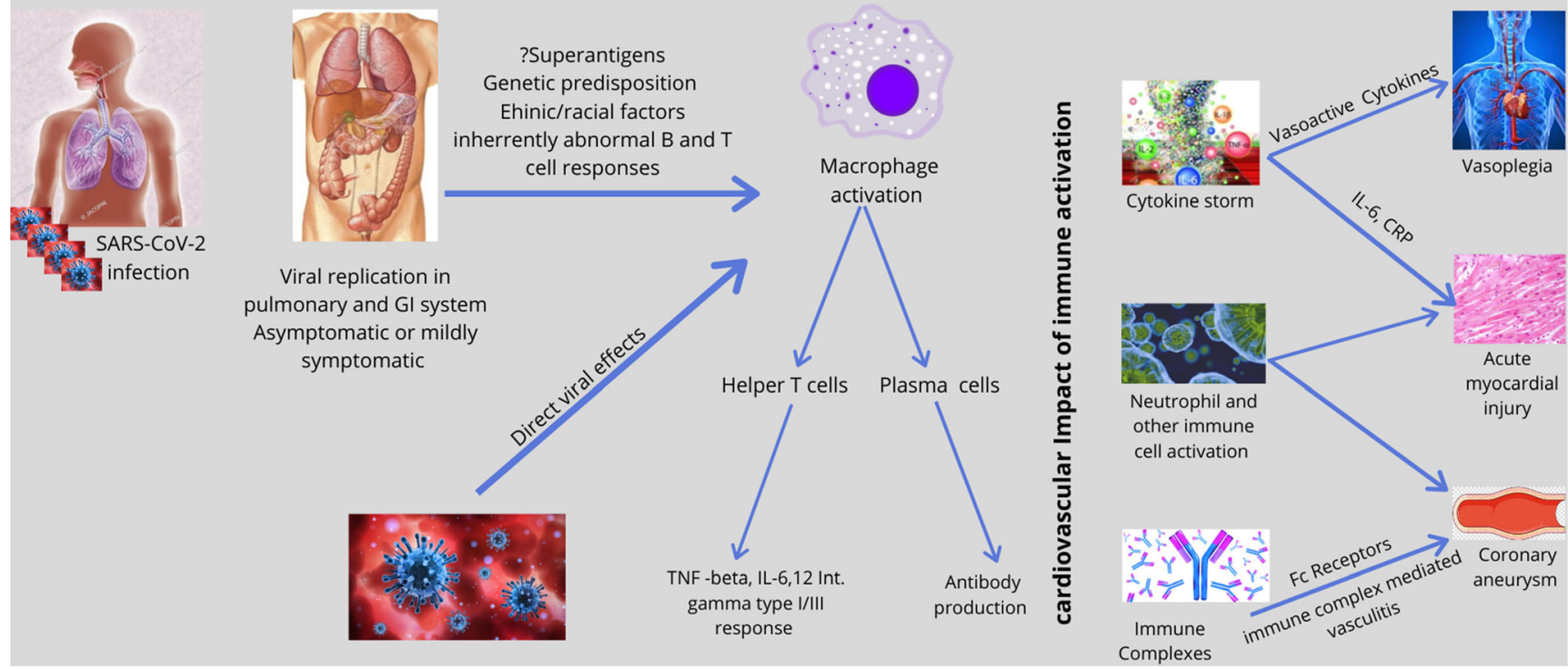

Fig. 1 The possible mechanism o cardiovascular involvement in multi-system inflammatory syndrome in children (MIS-C) following SARS-CoV-2 Infection 
MIS-C like illness from China and Japan and most of their paediatric cases are mild [41]. Interestingly the prevalence of Kawasaki disease in these countries is one of the highest in the world. The more frequent development of MIS-C in older children and adolescents and black race is likely due to the variability in expression of angiotensin-converting enzyme 2 (ACE 2) and genetically determined aberrant $\mathrm{T}$ cell and $\mathrm{B}$ cell responses to SARS-CoV-2 infection. Children's immune systems are in the developing stage and may respond to challenges differently from adult immune systems. The immature respiratory tract and immune system in children contribute to severe illness in the case of other viral respiratory diseases like influenza or respiratory syncytial virus [42]. It is also speculated that children respond differently to SARS-CoV-2 infection because the maturity and function (e.g. binding ability) of ACE2 in children may be lower and circulating levels of the enzyme may be higher than that in adults [43].

\section{Management}

The primary aim of therapy is to reduce the systemic inflammation, protect the organs and decrease or prevent complications like coronary aneurysms and death. The clinical management should be informed by clinical presentation, and the management of such cases requires multi-disciplinary team (general paediatrics, infectious diseases, cardiology, intensive care, haematology, immunology, pharmacy and rheumatology). Children with moderate to severe symptoms need intensive care support with appropriate therapies according to organ involvement including antimicrobial drugs. The role of antivirals is not clear at present [24]. The choice of treatment in any viral disease depends upon the stage of the disease and perceived/actual reasons for deterioration. If the clinical deterioration is due to replication of virus, antivirals may be beneficial, or if it is due to cytokine response, then immunomodulatory therapy may be useful. It is proposed that MIS-C is immune-mediated multiorgan damage; thus immunomodulatory therapy is preferred. The most common therapies tried for MIS-C are intravenous immunoglobulins, systemic glucocorticoids, anti-IL-1 receptor antagonist, anti-IL-6 receptor antagonist and TNF alpha antagonists with positive outcomes (Table 4). At present, there is no randomized controlled trial available to judge the relative efficacies of these medications, but certain management guidelines are available based on expert opinion [44].

\section{Future Direction}

In future as more clinical data and exact pathogenetic mechanisms need to be elucidated, to determine the risk factors, prognostic markers, rational management and prevention strategies. Of note genetic and immunologic studies to measure the immune response, studies with control arms including children who are seropositive for SARS-CoV-2 antibodies but no disease and research related to the vaccine will be crucial. Theoretically, SARS-CoV-2 vaccine-related immune response may precipitate MIS-C. Research is also needed in direction of the exact cause of heart failure and mechanisms of myocarditis, especially histopathology studies, to determine the presence or absence of active viral replication in myocardium and type of immune damage. Longitudinal studies will be the answer to the natural history of coronary aneurysm and their propensity to cause myocardial infarction.

\section{Conclusion}

We are early in experience with the this new entity and there are certain unanswered questions relating to effective treatments to prevent progression to severe disease, treatments to prevent the formation of coronary aneurysms and most importantly what is the natural history of such aneurysms and how to follow-up such patients? To answer all these questions, we need studies with wider case definitions which include milder forms of disease and control arms with positive serology for SARS-CoV-2 but no disease. In coming time, the most challenging task will be to define the actual pathophysiological mechanisms and accordingly develop early diagnostic tools and effective therapies. Due to the lack of longitudinal data, at present, it will be difficult to plan for surveillance and community care following recovery from severe illness.

Authors' Contribution Both the authors were involved in conceptualisation, drafting and final editing of the manuscript.

Funding This study received no funding.

Data Availability The data underlying this article are available in the article.

\section{Compliance with Ethical Standards}

Ethical Approval This article does not contain any studies with human participants or animals performed by any of the authors.

Consent for Publication N/A

Conflict of Interest Both authors declare no conflict of interest.

Informed Consent Not Applicable.

\section{References}

1. Huang C, Wang Y, Li X, Ren L, Zhao J, Hu Y, et al. Clinical features of patients infected with 2019 novel coronavirus in 
Wuhan, China. Lancet. 2020;395(10223):497-506. https://doi.org/ 10.1016/S0140-6736(20)30183-5 Erratum in: Lancet. 2020 Jan 30.

2. Coronavirus Disease 2019 in Children - United States, February 12-April 2, 2020. MMWR Morb Mortal Wkly Rep. 2020;69:4226. https://doi.org/10.15585/mmwr.mm6914e4.

3. Castagnoli R, Votto M, Licari A, Brambilla I, Bruno R, Perlini S, et al. Severe acute respiratory syndrome coronavirus 2 (SARSCoV-2) infection in children and adolescents: a systematic review. JAMA Pediatr. 2020;174:882-9. https://doi.org/10.1001/ jamapediatrics.2020.1467.

4. Malviya A, Yadav R. COVID -19 pandemic and paediatric population with special reference to congenital heart disease. Indian Heart J. 2020;72:141-4. https://doi.org/10.1016/j.ihj.2020.06.001.

5. Dong Y, Mo X, Hu Y, Qi X, Jiang F, Jiang Z, et al. Epidemiological characteristics of 2143 pediatric patients with 2019 coronavirus disease in China. Paediatrics. 2020. https://doi.org/10.1542/peds. 2020-0702.

6. Xia W, Shao J, Guo Y, Peng X, Li Z, Hu D. Clinical and CT features in pediatric patients with COVID-19 infection: different points from adults. Pediatr Pulmonol. 2020;55(5):1169-74. https://doi.org/10.1002/ppul.24718.

7. Riphagen S, Gomez X, Gonzalez-Martinez C, Wilkinson N, Theocharis P. Hyperinflammatory shock in children during COVID-19 pandemic. Lancet. 2020;395(10237):1607-8. https:// doi.org/10.1016/S0140-6736(20)31094-1.

8. Jones VG, Mills M, Suarez D, Hogan CA, Yeh D, Segal JB, et al. COVID-19 and Kawasaki disease: novel virus and novel case. Hosp Pediatr. 2020;10(6):537-40. https://doi.org/10.1542/hpeds. 2020-0123.

9. Paediatric Intensive Care Society (PICS) Statement: increased number of reported cases of novel presentation of multisystem inflammatory disease. Available at https://picsociety.uk/wp-content/ uploads/2020/04/PICS-statement-re-novel-KD-C19-presentationv2-27042020.pdf. Accessed on May 15, 2020.

10. Verdoni L, Mazza A, Gervasoni A, Martelli L, Ruggeri M, Ciuffreda M, et al. An outbreak of severe Kawasaki-like disease at the Italian epicentre of the SARS-CoV-2 epidemic: an observational cohort study. Lancet. 2020;395(10239):1771-8. https://doi. org/10.1016/S0140-6736(20)31103-X.

11. Grimaud M, Starck J, Levy M, Marais C, Chareyre J, Khraiche D, et al. Acute myocarditis and multisystem inflammatory emerging disease following SARS-CoV-2 infection in critically ill children. Version 2. Ann Intensive Care. 2020;10(1):69. https://doi.org/10. 1186/s13613-020-00690-8.

12. Whittaker E, Bamford A, Kenny J, Kaforou M, Jones CE, Shah P, et al. Clinical characteristics of 58 children with a pediatric inflammatory multisystem syndrome temporally associated with SARSCoV-2. JAMA. 2020:e2010369. https://doi.org/10.1001/jama. 2020.10369

13. Royal College of Paediatrics and Child Health. Guidance - paediatric multisystem inflammatory syndrome temporally associated with COVID-19. https://www.rcpch.ac.uk/resources/guidancepaediatric-multisystem-inflammatory-syndrome-temporallyassociated-covid-19. Accessed 19th May 2020

14. World Health Organization Scientific Brief: Multisystem inflammatory syndrome in children and adolescents with COVID-19. Available at: World Health Organization Scientific Brief: Multisystem inflammatory syndrome in children and adolescents with COVID-19. Accessed on May 17, 2020)

15. Cheung EW, Zachariah P, Gorelik M, Boneparth A, Kernie SG, Orange JS, et al. Multisystem inflammatory syndrome related to covid-19 in previously healthy children and adolescents in New York City. JAMA. 2020:e2010374. https://doi.org/10.1001/jama. 2020.10374 .

16. Dallan C, Romano F, Siebert J, Politi S, Lacroix L, Sahyoun C. Septic shock presentation in adolescents with COVID-19. Lancet
Child Adolesc Health. 2020;4(7):e21-3. https://doi.org/10.1016/ S2352-4642(20)30164-4.

17. Toubiana J, Poirault C, Corsia A, Bajolle F, Fourgeaud J, Angoulvant F, et al. Kawasaki-like multisystem inflammatory syndrome in children during the covid-19 pandemic in Paris, France: prospective observational study. BMJ. 2020;369:m2094. https:// doi.org/10.1136/bmj.m2094.

18. Feldstein LR, Rose EB, Horwitz SM, Collins JP, Newhams MM, Son MBF, et al. Multisystem Inflammatory Syndrome in U.S. Children and Adolescents. N Engl J Med. 2020: NEJMoa2021680. https://doi.org/10.1056/NEJMoa2021680.

19. Dufort EM, Koumans EH, Chow EJ, Rosenthal EM, Muse A, Rowlands J, et al. Multisystem Inflammatory Syndrome in Children in New York State. N Engl J Med. 2020: NEJMoa2021756. https://doi.org/10.1056/NEJMoa2021756.

20. Centres for Disease Control and Prevention. Emergency preparedness and response: a multisystem inflammatory syndrome in children (MIS-C) associated with coronavirus disease 2019 (COVID19). Health advisory https://emergency.cdc.gov/han/2020/ han00432.asp. Accessed on May 17, 2020.

21. Capone CA, Subramony A, Sweberg T, Schneider J, Shah S, Rubin $\mathrm{L}$, et al. Characteristics, cardiac involvement, and outcomes of multisystem inflammatory disease of childhood (MIS-C) associated with SARS-CoV-2 infection. J Pediatr. 2020;S0022-3476(20): 30746. https://doi.org/10.1016/j.jpeds.2020.06.044.

22. Levin M. Childhood multisystem inflammatory syndrome - a new challenge in the pandemic [published online ahead of print, 2020 Jun 29]. N Engl J Med. 2020. https://doi.org/10.1056/ NEJMe2023158.

23. Davies P, Evans C, Kanthimathinathan HK, Lillie J, Brierley J, Waters $\mathrm{G}$, et al. Intensive care admissions of children with paediatric inflammatory multisystem syndrome temporally associated with SARS-CoV-2 (PIMS-TS) in the UK: a multicentre observational study. Lancet Child Adolesc Health. 2020;4:669-77. https://doi. org/10.1016/S2352-4642(20)30215-7.

24. Belhadjer Z, Méot M, Bajolle F, Khraiche D, Legendre A, Abakka $\mathrm{S}$, et al. Acute heart failure in multisystem inflammatory syndrome in children (MIS-C) in the context of global SARS-CoV-2 pandemic. Circulation. 2020. https://doi.org/10.1161/ CIRCULATIONAHA.120.048360.

25. Ramcharan T, Nolan O, Lai CY, Prabhu N, Krishnamurthy R, Richter AG, et al. Paediatric inflammatory multisystem syndrome: temporally associated with SARS-CoV-2 (PIMS-TS): cardiac features, management and short-term outcomes at a UK tertiary paediatric hospital. Pediatr Cardiol. 2020:1-11. https://doi.org/10. 1007/s00246-020-02391-2.

26. McCrindle BW, Rowley AH, Newburger JW, et al. Diagnosis, treatment, and long-term management of Kawasaki Disease: a scientific statement for health professionals from the American Heart Association [published correction appears in circulation. 2019 Jul 30;140(5):e181-e184]. Circulation. 2017;135(17):e927-99. https://doi.org/10.1161/CIR.0000000000000484.

27. Newburger JW, Sleeper LA, McCrindle BW, Minich LL, Gersony W, Vetter VL, et al. Randomized trial of pulsed corticosteroid therapy for primary treatment of Kawasaki disease. N Engl J Med. 2007;356(7):663-75. https://doi.org/10.1056/NEJMoa061235.

28. Burns JC, Shike H, Gordon JB, Malhotra A, Schoenwetter M, Kawasaki T. Sequelae of Kawasaki disease in adolescents and young adults. J Am Coll Cardiol. 1996;28:253-7.

29. Rowley AH. Multisystem inflammatory syndrome in children (MIS-C) and Kawasaki disease: two different illnesses with overlapping clinical features. J Pediatr. 2020;224:129-32. https://doi. org/10.1016/j.jpeds.2020.06.057.

30. Shulman ST. Pediatric COVID-associated multi-system Inflammatory Syndrome (PMIS). J Pediatr Infect Dis Soc. 2020;9:285-6. https://doi.org/10.1093/jpids/piaa062. 
31. Pan Y, Zhang D, Yang P, Poon LLM, Wang Q. Viral load of SARS-CoV-2 in clinical samples. Lancet Infect Dis. 2020;20: 411-2.

32. Zhou F, Yu T, Du R, Fan G, Liu Y, Liu Z, et al. Clinical course and risk factors for mortality of adult inpatients with COVID-19 in Wuhan, China: a retrospective cohort study. Lancet. 2020;395(10229):1054-62. https://doi.org/10.1016/S01406736(20)30566-3 Erratum in: Lancet. 2020 Mar 28;395(10229): 1038.

33. Liu L, Wei Q, Lin Q, Fang J, Wang H, Kwok H, et al. Anti-spike IgG causes severe acute lung injury by skewing macrophage responses during acute SARS-CoV infection. JCI Insight. 2019;4(4):e123158. https://doi.org/10.1172/jci.insight.123158.

34. Katzelnick LC, Gresh L, Halloran ME, Mercado JC, Kuan G, Gordon A, et al. Antibody-dependent enhancement of severe dengue disease in humans. Version 2. Science. 2017;358(6365):92932. https://doi.org/10.1126/science.aan6836.

35. Mayadas TN, Tsokos GC, Tsuboi N. Mechanisms of immune complex-mediated neutrophil recruitment and tissue injury. Circulation. 2009;120(20):2012-24. https://doi.org/10.1161/ CIRCULATIONAHA.108.771170.

36. Nagelkerke SQ, Kuijpers TW. Immunomodulation by IVIg and the Role of Fc-gamma Receptors: Classic Mechanisms of Action after all? Front Immunol. 2015;5:674. Published 2015 Jan 21. https:/doi. org/10.3389/fimmu.2014.00674.

37. Menikou S, Langford PR, Levin M. Kawasaki disease: the role of immune complexes revisited. Front Immunol. 2019;10:1156. Published 2019 Jun 12. https://doi.org/10.3389/fimmu.2019. 01156.
38. Rowley AH. Understanding SARS-CoV-2-related multisystem inflammatory syndrome in children. Nat Rev Immunol. 2020;20: 453-4. https://doi.org/10.1038/s41577-020-0367-5.

39. Pathan N, Hemingway CA, Alizadeh AA, Stephens AC, Boldrick $\mathrm{JC}$, Oragui EE, et al. Role of interleukin 6 in myocardial dysfunction of meningococcal septic shock. Lancet. 2004;363(9404):2039. https://doi.org/10.1016/S0140-6736(03)15326-3.

40. Onouchi Y, Ozaki K, Burns JC, Shimizu C, Terai M, Hamada H, et al. A genome-wide association study identifies three new risk loci for Kawasaki disease. Nat Genet. 2012;44(5):517-21. https://doi. org/10.1038/ng.2220.

41. Xu S, Chen M, Weng J. COVID-19 and Kawasaki disease in Children. Pharmacol Res. 2020;159:104951. https://doi.org/10. 1016/j.phrs.2020.104951.

42. Hong L, Luo Y. Respiratory viral infections in infants: causes, clinical symptoms, virology, and immunology. Clin Microbiol Rev. 2010;23:74-98.

43. Elena C, Carmine V, Alessandro PA. COVID-19 infection and circulating ACE2 Levels: protective role in women and children. Front Pediatr. 2020;8:206. https://doi.org/10.3389/fped.2020. 00206;2296-2360.

44. Nakra NA, Blumberg DA, Herrera-Guerra A, Lakshminrusimha S. Multi-System Inflammatory Syndrome in Children (MIS-C) Following SARS-CoV-2 infection: review of clinical presentation, hypothetical pathogenesis, and proposed management. Children (Basel). 2020;7(7):E69. Published 2020 Jul 1. https://doi.org/10. 3390/children7070069.

Publisher's Note Springer Nature remains neutral with regard to jurisdictional claims in published maps and institutional affiliations. 